DOI: $10.17805 /$ trudy.2018.2.3

\title{
ИНТЕРПРЕТАЦИИ КУЛЬТУРЫ В КОНТЕКСТЕ МИФА
}

\author{
А. Я. Флиер \\ Российский научно-исследовательский институт \\ культурного и природного наследия им. Д. С. Лихачева
}

Аннотация: В статье представлена анализ миф и мифологии как системообразующего контекста актуальной интерпретации культуры, как распространенная форма массового сознания.

Текст доклада автора на Всероссийской научной конференции «Культура между Логосом и Мифом: к проблеме бессознательного (к 80-летию А.Э. Воскобойникова)», которая прошла в Московском гуманитарном университете 26-27 октября 2017 года.

Ключевые слова: культурология; теория культуры; миф; культура; мифология; массовое сознание

\section{INTERPRETATIONS OF CULTURE IN THE CONTEXT OF MYTH}

\author{
A. Ya. Flier
}

Russian Scientific Research Institute for Cultural and Natural Heritage named after D. Likhachev

Аннотация: The paper presents an analysis of myth and mythology as the system-forming context of the acute interpretation of culture, as a common form of mass consciousness.

The text of the author's speech at the All-Russian Scientific Conference "Culture between Logos and Myth: on the Issue of the Unconscious (dedicated to the 80th anniversary of A. E. Voskoboynikov)", which was held at Moscow University for the Humanities on 26-27 October 2017.

Ключевые слова: culturology; culture theory; myth; culture; mythology; mass consciousness

Если редуцировать общую теорию относительности Альберта Эйнштейна до образа, понятного любому гуманитарию, то можно сказать, что эта теория гласит о контекстуальной зависимости измеряемых параметров физического мира (см. об этом: Айзексон, 2015). Значения этих измеряемых параметров зависят от пространственно-временного контекста, в котором происходит измерение, и при изменении контекста меняются и значения параметров. Например, расстояние от Земли до ближайшей к нам звезды 
Научные труды Московского гуманитарного университета 2018 № 2

альфа Центавра при наблюдении с Земли имеет одно значение, а при измерении его из другой точки Космоса будет иным. Но не потому, что это расстояние изменится, а потому что изменится пространственно-временной контекст измерения.

Но практически такой же контекстуальной зависимостью обладают и смыслы/значения культурных артефактов. Эти смыслы/значения полностью определяются контекстом их интерпретации. Например, «Мона Лиза» Леонардо да Винчи имеет один смысл в качестве экспоната Лувра, а если ее перенести в джунгли Новой Гвинеи и сделать объектом культа местных папуасов, то этот смысл изменится и уже будет связан с мифологией папуасов, хотя само полотно картины останется неизменным. Очень показателен в этом плане и другой пример. Вспомним, как музыкальная тема «Полета валькирий» Рихарда Вагнера использована в фильме Френсиса Кополлы «Апокалипсис сегодня» в качестве звукового фона атаки американских вертолетов на вьетнамскую деревню. И весь смысл этой музыки меняется, потому что изменился контекст ее интерпретации, хотя сама музыкальная тема звучит в классическом варианте, как в опере «Валькирия».

Таких примеров можно привести множество. Здесь значим сам факт доминантной обусловленности интерпретации культурного феномена внешним контекстом, в котором происходит данная интерпретация.

Возникает вопрос: является ли подобный контекст случайным (ситуативным), и любая совокупность внешних факторов может рассматриваться как значимый контекст? Или же есть определенная закономерность в том, какие феномены окружающей реальности становятся значимым контекстом, детерминирующим интерпретацию культурных артефактов? Определенно и аргументировано ответить на этот вопрос сложно. Но я чисто умозрительно полагаю, что в роли значимого контекста выступают лишь определенные внешние факторы, и одним из наиболее распространенных и очевидных таких факторов является актуальная для сообщества (или его сегмента) мифология.

Здесь сразу же следует оговориться, что под мифологией мной понимается не только «... "объяснение" природы через перенесение на нее отношений между людьми, характерных для первобытнообщинной формации (родовой социоморфизм), а также свойств человека (антропоморфизм)» (А. Ф. Лосев) (Лосев, 1963: 134), или иные особенности сознания человека первобытной стадии развития (Токарев, Мелетинский, 1988: 11-20), что обычно фигурирует в науке. Это классическая трактовка. Мною же миф понимается как распространенная форма массового сознания любого времени, интерпретирующая актуальные сюжеты без достаточных на то фактологических и системно-научных оснований. Современные мифологемы 
базируются главным образом на слухах, сплетнях и иной досужей болтовне, а порой сознательно культивируются властью или производителем какого-либо товара и распространяются через СМИ с целью стимулирования ажиотированной политической лояльности или ажиотажного спроса на какой-то товар. Миф и массовый ажиотаж в наши дни уже не разделимы.

Если миф, изучаемый классиками мифологической науки, можно с известной долей условности назвать этнографическим (разумеется, он содержательно и проблемно шире, но этнографическая составляющая здесь преобладает), то, к примеру, специализированной мифологией власти является политическая идеология, мифологией социальной престижности - мода и т. п. Поэтому сразу предупрежу читателя, что миф/мифология как системообразующий контекст актуальной интерпретации культуры будет рассматриваться здесь в широком понимании как распространенная форма массового сознания.

Почему же именно мифология выступает в качестве универсального контекста культурных интерпретаций? Я думаю, что основная причина в ее массовой распространенности. Ведь помимо упомянутых выше системных и самодостаточных мифологий элементы мифологизации присутствуют в любом массово распространенном идейном сюжете. Это уже отмечалось в мифологизированном феномене «народного христианства», заметно отличающегося от «книжного христианства» образованных слоев (см. об этом, например: Брагина и др., 1990; Левин, 2004 и др.), в наивном мифологизированном национализме масс (см., например: Андерсон, 2001; Балибар, Валлерстайн, 2003 и др.). Уже упоминавшийся А. Ф. Лосев полагал, что «... Миф не есть выдумка или фикция, не есть фантастический вымысел, но - логически, т. е. прежде всего диалектически, необходимая категория сознания и бытия вообще» (Лосев, 1994: 71).

Говоря иначе, миф - это непрофессиональная, но по-своему логичная интерпретация какой-либо проблемы в массовом сознании, как правило, весьма далекая от сложной и противоречивой реальности, изучаемой профессионалами. Но профессиональные интерпретации - это удел специалистов с профильным образованием, а миф - это преобладающий вариант интерпретации различных актуальных явлений необразованными массами. Масса в своих миропредставлениях опирается не столько на достоверные знания об окружающей реальности, сколько на различные мифологемы по ее поводу. Такие мифологемы раньше стихийно рождались в народной среде, а ныне целенаправленно формулируются политтехнологами и внедряемыми в массовое сознание с помощью СМИ. Поэтому интерпретация большинства культурных артефактов осуществляется преимущественно в рамках той или иной социальной мифологии как наиболее распространен- 
Научные труды Московского гуманитарного университета 2018 № 2

ной формы сознания и миропредставления народных масс. Такая интерпретация легче будет понята и усвоена населением.

Вместе с тем, я полагаю, что эта зависимость интерпретации культурных артефактов от той или иной мифологии является пластичной, разной в разных социальных типах культуры и социальных группах и даже в разные периоды истории.

В культуре традиционного типа, называемой народной (я предпочитаю называть ее культура-обычай), преобладавшей абсолютно в первобытности и преимущественно в аграрный период (как культура основной массы земледельческого населения), конечно, доминировала этнографическая мифология, представлявшая собой системный контекст культуры этого типа. Эта мифология хорошо изучена наукой, являясь существенным разделом религиоведения и этнографии (см., например, уже упоминавшуюся энциклопедию: Мифы народов мира, 1988). Наиболее значимые параметры этой мифологии выражены в системе взглядов, основанной на иррациональном способе восприятия и отражения мира. Для мифологического сознания этого типа свойственно стремление к познанию мира посредством мистической реконструкции его генезиса (т. е. посредством формирования легенд о его происхождении) и латентная попытка объяснить структуру Космоса через аналогию с хорошо знакомой структурой социального устройства общества (см. об этом: Франкфорт и др., 1984). Подобная мифология формировалась предположительно в эпоху позднего палеолита, достигла апогея в так называемый «варварский» (догосударственный) период развития и весьма эффективно служила средством регуляции поведения и сознания людей и на более поздних этапах истории. Как крестьянская система сознания она в том или ином варианте сохранилась и до сих пор. Среди характерных признаков мифологического сознания этого типа принято выделять такие представления о бытии, как:

- Универсальность существования человека в мире: человек не выделяет себя из природы, не относится к миру как к объекту познания и преобразования, а к самому себе как к субъекту этого познания, но стремится преимущественно к магическим, чувственным формам взаимодействия с миром и его процессами и др.

- Холистичность и синкретичность мира: доминирует нерасчлененная целостность в мироощущении; бытие практически не дифференцируется на функциональные и структурные сегменты, на прошлое, настоящее и будущее, на объект и означающий его знак или слово, на практическое действие и символизирующий его ритуал. Весьма смутными являются представления о причинно-следственной детерминации событий и явлений. Преобладает хаотическое смешение в восприятии сакрального и мирского, 
живого и косного, человеческого и природного, реального и вымышленного, неизбежного и случайного и т. п.

- Цикличность восприятия времени и динамичность восприятия пространства: при крайней скудости представлений о линейном времени и преобладании представлений о круговороте времен - вечном возвращении (см. об этом: Элиаде, 1998), доминирует идея неизменной вечности, в которой пребывает мир. Перемены в бытии воспринимаются как иллюзия и интерпретируются как неизбежный циркулярный повтор событий в жизни людей, деяниях богов и пр. Пространство измеряется временем, потребным на его преодоление; структура мироздания ощущается как еще не законченная, формирующаяся, «растущая», вращающаяся вокруг некой сакральной оси, «центра мира» и т. п. В целом космогоническое мировосприятие доминирует над космологическим (Флиер, 2014: 43-45; см. об этом также: Горяинова, Электр. ресурс).

Интерпретация культурных артефактов традиционной (народной) культурой в целом осуществляется в русле контекста этих характеристик, хотя, конечно, о детальном соответствии одного другому речь не идет. Наиболее полное соответствие этим характеристикам имеет место в культурах сообществ, находящихся еще на первобытном этапе развития. У народов, развившихся до аграрного и, тем более, индустриального этапов, подобные характеристики крестьянских культур имеют более фрагментированный и менее выраженный характер. Но основной системный контекст интерпретации таких культур остается подобным описанному. Культурный артефакт в рамках этой мифологии интерпретируется путем соотнесения его смыслов с господствующими представлениями данной этнической среды. Он принимается, если обнаруживаются точки смыслового совпадения, и отвергается, если такого соответствия нет.

В аграрную эпоху с возникновением городов и государств рождаются профессии правителя, воина и священнослужителя, а также обслуживающих их ремесленников и художников, требующие уже специализированных знаний и навыков, т. е. специального обучения. С ними формируется и новый тип культуры, называемый у разных исследователей элитарным, креативным, специализированным и др. Я предпочитаю называть его культурой-идеологией. В аграрную эпоху эта культура концентрировалась в среде земельной аристократии и ее обслуги; в индустриальную эпоху ей стали овладевать образованные выходцы из «третьего сословия»; а ныне к ней в той или иной степени принадлежит вся масса горожан, занятых специализированным трудом, требующим высшего образования. Впрочем, это касается только профессиональной деятельности, а не в потребления и досуга.

Отличительными чертами этой культуры стали: 
Научные труды Московского гуманитарного университета 2018 № 2

- Наличие у ее представителей фундаментальных знаний и практических навыков по профессии, получаемых в процессе специализированного образования.

- Высокая общая гуманитарная эрудиция, хорошее знание литературы и искусства, тенденций мировой политики, новостей «высшего света», благородных манер поведения и т.п.

- Близость круга интересов ее адептов к политической власти, та или иная включенность в обсуждение ее проблем (лояльная или оппозиционная).

- Подчеркнутая иерархичность представлений о социальном устроении общества и пр.

Эта иерархичность представлений об обществе стала играть особую роль в формировании политической идеологии как теоретической квинтэссенции подобной элитарной культуры. Идеология - это особая мифология власти, эксплуатирующая иллюзию ее всемогущества, построенная на идее социального неравенства людей, лучше всего проиллюстрированная феодальной сословной пирамидой, постоянно подчеркивающая разную социальную ценность разных «этажей» этой пирамиды и т. п. (см., например: Введенский, 1952). Именно этот тип мифологии и стал контекстом интерпретации артефактов элитарной культуры, так или иначе выражающих свою «околовластную» позицию.

На раннем этапе существования этой культуры (в аграрную эпоху) особую роль в ее функционировании и интеллектуальном обеспечении играла религия. Религия - это иное по сравнению с ранней этнографической мифологией проявление иррационального сознания людей, представляющее собой попытку выстроить целостное системное мировоззрение, упорядочить свои представления о бытии и создать психологически комфортное объяснение существующему миропорядку на основании идеи божественного сотворения и управления миром. По сравнению с ранней мифологией религия является гораздо более систематизированным учением о генезисе и природе бытия, а также правилах социального поведения человека, основанных на сакральной конвенции между Богом и людьми, выраженной в той или иной форме самого религиозного учения. По мере своего исторического развития религия, не отказываясь от решения мировоззренческих задач, приобретала все более выраженные социально-регулятивные и общие идеологические функции. Ключевыми вопросами религии являются отношение человека к конечности бытия, к феномену смерти, к вопросам греха, воздаяния за него и возможности его искупления, к проблемам нравственного существования и т. п. Как правило, в основании религиозного представления о структуре мира стоит противопоставление инфернального 
«абсолютного Добра» столь же инфернальному «абсолютному Злу» (Флиер, 2014; см. об этом также: Пелипенко, 2012). В аграрную эпоху религия в большой мере являлась общемировоззренческой и политической идеологией общества своего времени.

На индустриальном этапе развития социальное влияние религии стало слабеть, и ее системообразующее место регулятора общественного сознания заняла собственно идеология в ее откровенно политизированном виде. По существу идеология отпочковалась от религии, будучи ранее ее органичной частью. При этом она сохранила функцию мифологии власти и даже усилила ее воздействие на население, благодаря возможностям СМИ. Контекстуальная роль этой мифологии по отношению к артефактам культуры выражена прежде всего в том, что культурное качество этих артефактов стало оцениваться главным образом по их политической полезности. Эта тенденция появилась еще в XVII веке и стала абсолютно доминировать в последующем. Культура в глазах власти делится на полезную, бесполезную и вредную. Например, Пушкин, по мнению Николая I, был талантливым, но бесполезным литератором, а Лермонтов - просто вредным. Можно привести примеры и из практики сегодняшнего дня. Это особенно ярко проявляется в отношении власти к искусству, но фактически имеет место в отношении всей культуры, особенно профессиональной.

Примерно в середине XIX века на волне научно-технической революции в Западной Европе, а затем в Северной Америке начался бум урбанизации, и миллионы крестьян переселились в города, где для них расширялись возможности заработка. В их среде стихийно начала складываться культура повседневного потребления и заполнения досуга, ныне называемая массовой. Я определяю ее как культуру-референцию. Эта культура не отличалась большими эстетическими достоинствами, но успешно выполняла функцию социально-психологической стабилизации новых горожан. В этой массовой культуре основным системообразующим элементом стала мода, взявшая на себя функцию ценностного контекста новой культуры. Это было обусловлено тем, что мода явилась внешним выражением (атрибутикой) социальной престижности, в тех формах, которые были актуальны для этой маргинальной среды. Модная одежда и весь имидж человека в определенном смысле свидетельствовали о его социальном успехе, о его конкурентоспособности. Для молодых женщин их модный внешний вид был условием их гендерного успеха. Мода превратилась в новую мифологию внешнего выражения социальной конкурентоспособности.

Разумеется, мода существовала и до появления массовой культуры, функционируя в основном в аристократической среде, тоже являясь выражением социальной престижности, выраженном в одежде, прическе, на- 
Научные труды Московского гуманитарного университета 2018 № 2

градах, украшениях и пр. Но она не играла такой демонстративно-регулятивной роли в повседневной жизни общества, и в ее функционировании не было такого ажиотажа, какие она приобрела в массовой культуре XX века. Тому способствовал ряд причин, которые сейчас рассматриваться не будут. Но если раньше мода в основном была выражением принадлежности человека к «высшему обществу», то мода массовой культуры XIX-XX вв. выражала гораздо более широкую гамму культурных смыслов, от мейнстримовских до контркультурных. Мода - в конечном счете - это подражание некому образцу, являющемуся в данный момент эталоном социальной престижности (см., например: Барт, 2003; Бодрийяр, 2006; Бурдье, 2005 и др.).

Пути культурного развития непредсказуемы, и ко второй половине XX века массовая культура превратилась в основную культуру повседневности практически всего городского населения развитых стран, и соответственно мода стала всеобщей мифологией социальной престижности для всех социальных групп современного города.

Конечно, интерпретировать современную массовую культуру в контексте моды довольно сложно, поскольку моды, как правило, актуальны по несколько штук одновременно, часто меняются и т. п., так что уследить за всем этим может только специалист. Но рядовому человеку и не нужно знать все эти детали; достаточно представлять себе основной модный тренд, чтобы с его позиций осуществлять интерпретацию артефактов и определять, насколько они могут быть востребованы на рынке культурной продукции.

Культурный феномен моды как иллюзии социальной успешности достаточно хорошо исследован семиотиками и социологами Роланом Бартом, Юлией Кристевой, Жаном Бодрийяром, Пьером Бурдье, Жилем Липовецки и др., что избавляет меня от необходимости специально останавливаться на этом. Вместе с тем, остается открытым вопрос: почему именно мода стала универсальным контекстом современной массовой культуры, главным критерием социальной приемлемости ее артефактов?

Вспомним в этой связи, что является критерием социальной приемлемости культуры в разных социальных средах. В зоне господства этнографической мифологии артефакты культуры оцениваются по своему coomветствию господствующим представлениям (как естественная часть общественного мировоззрения). В зоне господства идеологической мифологии артефакты культуры оцениваются по своей политической полезно$\boldsymbol{c m u}$ (как естественная часть реализуемой политики). Ну, а в зоне господства мифологии моды артефакты культуры оцениваются по своей социальной востребованности (как естественная часть рынка культурной продукции). 


\section{СПИСОК ЛИТЕРАТУРЫ}

Айзексон, У. (2015) Эйнштейн. Его жизнь и его Вселенная. М.: Corpus. $1020 \mathrm{c}$.

Андерсон, Б. (2001) Воображаемые сообщества. Размышления об истоках и распространении национализма. М.: Канон-Пресс-Ц. 320 с.

Балибар Э., Валлерстайн И. (2003) Раса, нация, класс. Двусмысленные идентичности. М.: Логос-Альтера, Ессе Ното. 272 с.

Барт, Р. (2003) Система моды. Статьи по семиотике культуры. М.: Издательство им. Сабашниковых. 512 с.

Бодрийяр, Ж. (2006) Общество потребления. Его мифы и структуры. М.: Культурная революция ; Республика. 269 с.

Брагина, Л. М., Гутнова, Е. В., Карпов, С. П. и др. (1990) Христианство, церковь и ереси в средние века // История Средних веков / под ред. 3. В. Удальцовой и С. П. Карпова. М.: Высшая школа. Т. 1.495 с.

Бурдье, П. (2005) О символической власти // Бурдье П. Социология социального пространства. М.-СПб.: Алетейя. С. 87-96.

Введенский, Б. А. (1952) Идеология // Большая советская энциклопедия: в 51 т. М.: Советская энциклопедия. Т. 17. С. 333-337.

Горяинова, О. И. Миф и культурный сценарий как механизмы социализации [Электронный ресурс] // lib2.znate.ru URL: http://lib2.znate.ru/docs/ index-300086.html (дата обращения: 15.02.2018).

Левин, И. (2004) Двоеверие и народная религия в истории России. М.: Индрик. 216 с.

Лосев, А. Ф. (1963) История античной эстетики (ранняя классика). М.: Высшая школа.

Лосев, А. Ф. (1994) Диалектика мифа // Лосев А. Ф. Миф. Число. Сущность. М.: Мысль.

Мифы народов мира (1988). Энциклопедия : в 2 т. М.: Наука. 720+671 с.

Пелипенко, А. А. (2012) Постижение культуры : в 2 ч. М. : РОССПЭН. Ч. 1. Культура и смысл. 607 с.

Токарев, С. А., Мелетинский, Е. М. (1988) Мифология // Мифы народов мира. Энциклопедия : в 2 т. М.: Наука. Т. 1. С. 11-20.

Флиер, А. Я. (2014) Избранные работы по теории культуры. М.: Согласие-Артем.

Франкфорт, Г., Франкфорт, Г. А., Уилсон, Дж., Якобсен, Т. (1984) В преддверии философии. Духовные искания древнего человека. М.: Наука. 236 с. Элиаде, М. (1998) Миф о вечном возвращении. СПб.: Алетейя. 258 с. Дата поступления: 12.12.2017 г. 
Флиер Андрей Яковлевич - доктор философских наук, профессор, главный научный сотрудник Российского научно-исследовательского института культурного и природного наследия им. Д. С. Лихачева. Адрес: 129366, Россия, г. Москва, ул. Космонавтов, д. 2. Тел.: +7 (495) 686-13-19. Эл. адрес: andrey.flier@yandex.ru

Flier Andrei Yakovlevich, Doctor of Philosophy, Professor, Chief Research Fellow, Russian Scientific Research Institute for Cultural and Natural Heritage named after D. Likhachev. Postal address: 2, Kosmonavtov St., Moscow, Russian Federation, 129366. Tel.: +7 (495) 686-13-19. E-mail: andrey.flier@yandex.ru

\section{Для цитирования:}

Флиер А. Я. Интерпретации культуры в контексте мифа [Электронный ресурс] // Научные труды Московского гуманитарного университета. 2018. №2. URL: http://journals.mosgu.ru/trudy/article/view/690 (дата обращения: дд.мм.гг.). DOI: 10.17805/trudy.2018.2.3 